\title{
Early immune responses to Dermatophagoides pteronyssinus and atopic predisposition
}

\author{
R G G Ruiz, D M Kemeny, F Mariani, J F Price
}

\begin{abstract}
Responses to the house dust mite during infancy may be important determinants of asthma in susceptible individuals. This study assessed early IgG subclass antibody responses to Dermatophagoides pteronyssinus in children of atopic parents. Sixteen atopic and 15 non-atopic children were selected from a birth cohort, and atopic status was established according to follow up over the first two years. $\mathrm{IgG}_{1}$ and $\mathrm{IgG}_{4}$ antibodies to $D$ pteronyssinus were measured by enzyme linked immunosorbent assay at 7 days and 3, 6, 12, and 24 months. In all children $D$ pteronyssinus $\mathrm{IgG}_{1}$ fell at 3 months (indicating maternal antibody loss), rose progressively to 12 months, and waned at 24 months. $D$ pteronyssinus IgG $_{4}$ was only detectable at 7 days. Children who were atopic by 2 years and therefore at greater risk of asthma, tended to have higher $D$ pteronyssinus IgG $_{1}$ at 6 and 12 months. These data suggest greater exposure or responsiveness to dust mite during infancy than in the second year.
\end{abstract}

\section{(Arch Dis Child 1992;67:1023-1026)}

House dust mite sensitivity has long been associated with asthma. ${ }^{1} \mathrm{~A}$ causal relationship has been inferred by the influence of the degree of mite exposure on the prevalence of asthma. ${ }^{23}$ Exposure during infancy may be particularly important in determining subsequent sensitisation to aeroallergens. ${ }^{4}$ Children with mite sensitivity are more likely to have been born in a season when mite counts were high, ${ }^{56}$ and higher levels of mite exposure in infancy have recently been reported among children who have persistent wheezing at 11 years. ${ }^{7}$

While much research has concentrated on measuring mite exposure, it is the individual response to this 'allergen load' that determines whether sensitisation ultimately occurs. There may be threshold levels of exposure for sensitisation ${ }^{1}$ but individuals with a similar genetic predisposition to atopy need not produce analogous immune responses to the same allergen load.

During the first year of life children are capable of mounting IgE antibody responses but they are usually to ingested allergens. ${ }^{8}{ }^{9} \mathrm{IgE}$ and IgG responses to aeroallergens are reported to be comparatively uncommon before the second year of life. ${ }^{8}$ It would be difficult to reconcile the importance of mite exposure during infancy with an apparent lack of immune responsiveness to the allergen at this time. We have recently demonstrated $\operatorname{IgG}_{1}$ subclass anti- bodies to the dust mite, Dematophagoides pteronyssinus, during the first year in most members of a group of 'unselected' children. ${ }^{10}$ The discrepancy with previous findings may be explained by our use of an enzyme linked immunosorbent assay (ELISA) with whole $D$ pteronyssinus extract instead of a radioimmunoassay for antibody to $D$ pteronyssinus $I{ }^{8}$ The latter assay was probably less sensitive as antibodies to $D$ pteronyssinus I may not represent the majority of dust mite antibodies at this age; they apparently constitute less than half of newly generated IgE antibodies to $D$ pteronyssinus in children. ${ }^{11}$

The present study aimed to measure IgG subclass antibody responses to whole $D$ pteronyssinus by ELISA in the first two years in subjects selected from a large cohort of children with a predisposition to atopy. The responses were compared between children with the most obvious evidence of atopy during the first two years, who were at greater risk of subsequent asthma, ${ }^{12}$ and those who were most clearly nonatopic despite their predisposition.

\section{Subjects and methods} COHORT DETAILS

All cohort members had been term neonates born between September 1987 and July 1989 in the Camberwell Health Authority. They had been identified by a history of atopic disease in both parents on antenatal questionnaires. If informed parental consent was obtained and atopy could be confirmed in at least one parent by a positive skin prick test, the infants were enrolled. ${ }^{13}$

They were assessed initially on day 7 when a blood sample was taken, and then at $3,6,12$, and 24 months to document atopic disease, perform skin prick tests, and obtain further blood samples. Additional examinations were made when coughs or suspicious rashes were reported.

Eczema diagnosed according to the guidelines of Hanifin and Rajka ${ }^{14}$ but modified for infants, ${ }^{15}$ wheezing on at least two separate occasions, and a history of recurrent immediate food reactions were each regarded as evidence of atopic disease.

Skin prick tests to dust mite (D pteronyssinus), cows' milk, hens' eggs, mixed grass pollens, cat fur (Bencard), mixed moulds (Dome/HollisterStier), and histamine $1 \mathrm{mg} / \mathrm{ml}$ and diluent control solutions (Bencard) were performed on the back in children and the forearm in parents. A weal after 15 minutes at least $2 \mathrm{~mm}$ in children, or $3 \mathrm{~mm}$ in adults, greater than that 
caused by the negative control was considered positive.

Sera were stored at $-20^{\circ} \mathrm{C}$ and subsequently analysed for total serum IgE antibody by an ultrasensitive $\mathrm{ELISA}^{16}$ in 7 day sera and by conventional two site ELISA $^{17}$ in all other samples. Undetectable concentrations were assigned a value of $0.01 \mathrm{IU} / \mathrm{ml}$ and the geometric mean and SD were calculated for each age group, although 7 day concentrations continued to have a very skewed distribution after log transformation.

The ethical committee of King's College Hospital had approved the method of follow up and all procedures.

\section{SUBJECT DETAILS}

Eighty of the original cohort completed the two year follow up. The first 16 (eight girls) classed as atopic and the first 15 (seven girls) considered non-atopic were selected for the study. The number of subjects was limited so that all samples from each age could be assayed together on a single microtitre plate thus eliminating interassay variability.

Children classed as atopic had: (i) positive skin tests to any allergen and (ii) evidence of atopic disease. Children were considered nonatopic if they met all of the following three criteria: (i) negative skin tests, (ii) a total IgE concentration less than $0.5 \mathrm{IU} / \mathrm{ml}$ at 7 days and below the geometric mean plus $1 \mathrm{SD}$ at any other age, and (iii) no evidence of atopic disease.

Of the 16 atopic children 11 had suffered with eczema (fig 1) and five had given positive skin tests to $D$ pteronyssinus.

\section{LABORATORY MATERIALS}

Nunc Immuno (MaxiSorp F96) microtitre plates were purchased from Gibco Ltd, horse serum from Sera Lab Ltd, Tween 20, alkaline phosphatase labelled rabbit antimouse IgG and p-nitrophenyl phosphate (PNP) from Sigma Ltd and IgG subclass-specific mouse monoclonal antibodies (clones NL16-IgG1, RJ4-IgG4 and 8a4-IgG) from Oxoid Ltd. Freeze dried whole dust mite extract ( $D$ pteronyssinus) was a kind gift from Dr $R$ Whal (Allergopharma, Reinbeck, Germany).

IgG SUBCLASS ASSAYS

$I G_{1}$ and $I_{g G}$ antibodies to $D$ pteronyssinus were

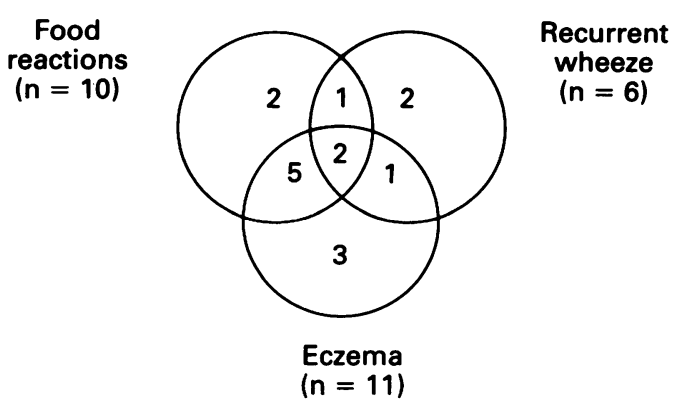

Figure 1 Categorisation of the 16 atopic children by evidence of atopic disease. measured by a two site ELISA ${ }^{18}$ in sera from 7 days, and 3, 6, 12, and 24 months in all 31 children. Incubation volumes were $50 \mu \mathrm{l}$ and temperatures were $4^{\circ} \mathrm{C}$ unless stated otherwise. There were three washes with phosphate buffered saline (PBS) containing 0.05\% Tween 20 between each incubation. The assay diluent was PBS containing $0.5 \%$ Tween 20 and $0.5 \%$ normal horse serum. Briefly, the microtitre plates were coated overnight with $10 \mu \mathrm{g} / \mathrm{ml} D$ pteronyssinus extract in pH 9.6 carbonate/bicarbonate buffer. The test sera, diluted $1 / 50$, were added in duplicate and incubated for two hours. There followed in sequence one hour incubations with monoclonal $\operatorname{IgG}_{1}$ or $\operatorname{IgG}_{4}(1 / 1000)$ and alkaline phosphatase-labelled antimouse IgG (1/300). Finally, $100 \mu \mathrm{l}$ of the substrate, PNP $(1 \mathrm{mg} / \mathrm{ml}$ in $\mathrm{pH} 9.8$ diethanolamine buffer) were added and after one hour at room temperature, the colour reaction was stopped with $50 \mu \mathrm{l} 3 \mathrm{M}$ sodium hydroxide and the optical density read at $405 \mathrm{~nm}$ in a Titertek multiskan plate reader (Flow Labs). Antibody concentrations were derived from a standard curve obtained using an IgG panreactive monoclonal antibody (clone 8a4) with dilutions of a high positive reference serum which was assigned 10000 arbitrary units $/ \mathrm{ml}(\mathrm{AU} / \mathrm{ml})$ when undiluted. ${ }^{18}$

\section{STATISTICAL ANALYSIS}

Even after $\log$ transformation $D$ pteronyssinus $I G_{1}$ antibody concentrations were not normally distributed at every age. However the log ratios of the concentrations at successive ages in each child did have normal distributions. Changes in $D$ pteronyssinus IgG $_{1}$ concentrations between two ages were therefore given as the geometric mean ratio of the concentrations at the two ages with a $95 \%$ confidence interval. The corresponding one sample $t$ tests gave the probability of the observed means if the true mean log ratio was zero (that is, if the ratio was 1 ); $p<0.0125$ was taken as the level of significance to allow for multiple comparisons (Bonferroni method). The Mann-Whitney test was used to analyse differences within age groups. The probability level for a significant difference was adjusted to $p<0.01$ to allow for five comparisons. Finally a sample size of 31 was theoretically able to have an $80 \%$ chance of detecting a significant difference at the $1 \%$ level of about $1 \cdot 2$ times the value of a SD. Bearing in mind that any SDs would be tentatively derived from actual study data with a less than perfect distribution, this meant that one might expect to detect differences down to 40-70 AU/ml, except at 7 days when variability was greatest.

\section{Results}

Every child had detectable concentrations of $\mathrm{IgG}_{1}$ antibody to $D$ pteronyssinus at all ages (fig 2). Concentrations were highest at 7 days, reached a nadir at 3 months, rose progressively up to 12 months but declined at 24 months. The $95 \%$ confidence intervals for the geometric mean ratio of concentrations at consecutive ages was calculated. One could be $95 \%$ sure that on average 12 month concentrations were between 


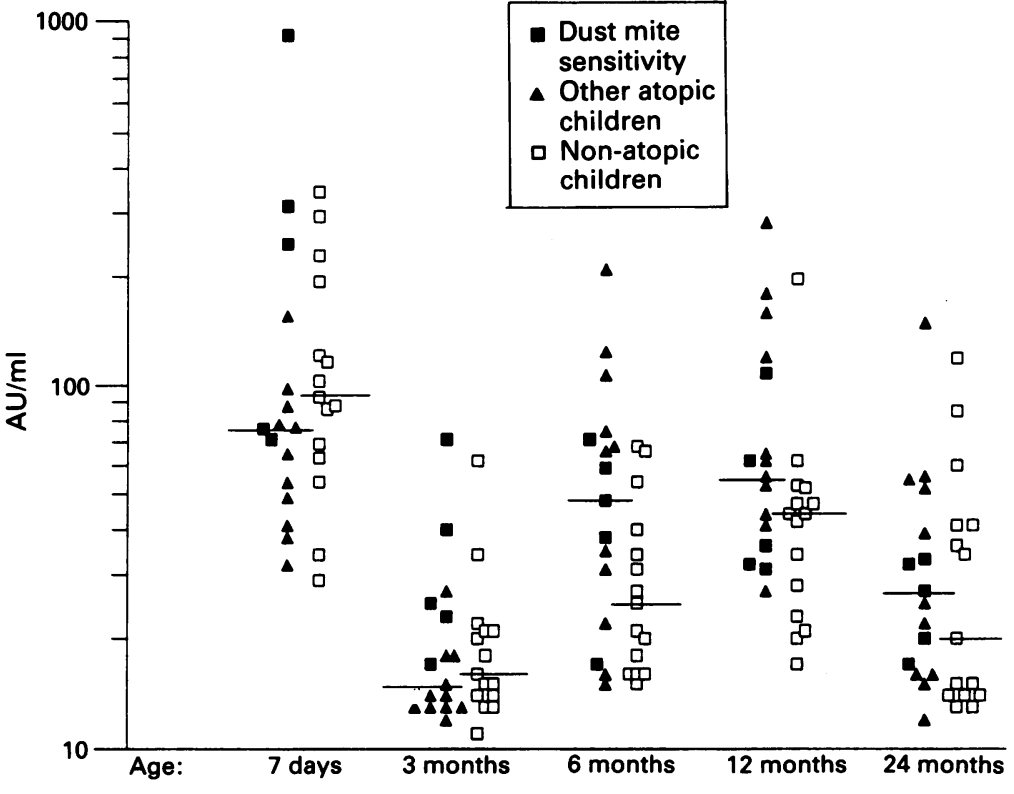

Figure 2 Concentrations of $\operatorname{Ig} G$, antibody to $D$ pteronyssinus in five atopic children with dust mite sensitivity, 11 other atopic children, and 15 non-atopic children during the first two years of life. Median concentrations in the atopic and non-atopic subgroups at each age are indicated by the horizontal bars.

1.43 to 2.40 times higher than concentrations at 24 months, with 1.86 times as the best estimate (table 1).

Atopic children tended to have higher $D$ pteronyssinus $\operatorname{IgG}_{1}$ concentrations than nonatopic counterparts at 6 and 12 months, with $0.01<\mathrm{p}<0.05$ (table 2). A trend for higher concentrations in the five dust mite sensitive individuals compared with the other 26 children was only seen at 3 months, with $p=0.03$ (fig 2). The six children who had recurrent wheezing had no tendency towards having higher values at any age.

$\mathrm{IgG}_{4}$ antibody to $D$ pteronyssinus was only found in 7 day sera and then in only three children. All three had mothers who had given florid skin reactions to $D$ pteronyssinus with weals of $6 \mathrm{~mm}, 8 \mathrm{~mm}$, and $11 \mathrm{~mm}$ in diameter respectively.

Table 1 Ratio of D pteronyssinus IgGI antibody concentrations between successive age groups

\begin{tabular}{lllr}
\hline $\begin{array}{l}\text { D pteronyssinus } I g G, \\
\text { concentration ratio }\end{array}$ & $\begin{array}{l}\text { Geometric mean } \\
\text { ratio }\end{array}$ & $\begin{array}{l}95 \% \text { Confidence } \\
\text { interval }\end{array}$ & $p$ Value \\
\hline 7 day:3 months & 5.15 & 4.27 to 6.21 & $<0.0001$ \\
3 months:6 months & 0.50 & 0.38 to 0.69 & 0.0001 \\
6 months: 12 months & 0.70 & 0.56 to 0.89 & 0.0040 \\
12 months:24 months & 1.86 & 1.43 to 2.40 & $<0.0001$ \\
\hline
\end{tabular}

"One sample $t$ test.

Table 2 Comparison of median (range) $D$ pteronyssinus IgG, antibody concentrations between atopic and non-atopic children

\begin{tabular}{llll}
\hline Age & $\begin{array}{l}\text { D pteronvssinus } I g\left(G_{1} \text { antibody }\right. \\
\text { concentration }(A U / m l)\end{array}$ & p Value \\
\cline { 2 - 3 } & $\begin{array}{l}\text { Atopic children } \\
(n=16)\end{array}$ & $\begin{array}{l}\text { Non-atopic children } \\
(n=15)\end{array}$ & \\
\hline 7 day & $76 \cdot 5(32-914)$ & $93(29-344)$ & 0.45 \\
3 months & $16(12-71)$ & $16(11-62)$ & 0.87 \\
6 months & $53 \cdot 5(15-210)$ & $25(15-68)$ & 0.03 \\
12 months & $59(27-283)$ & $44(17-197)$ & 0.04 \\
24 months & $26(12-149)$ & $20(13-119)$ & 0.54 \\
\hline
\end{tabular}

"Mann-Whitney test.

\section{Discussion}

The validity of this study depends on the specificity of the assay for IgG subclass antibodies to $D$ pteronyssinus. $\operatorname{IgG}_{1}$ antibody binding to $D$ pteronyssinus could be substantially inhibited by preincubation of the children's sera with the $D$ pteronyssinus extract and cross reactivity with a different antigen (ovalbumin) was minimal. This implied the antibodies had reasonable affinity and specificity. The assay was therefore regarded to measure genuine $D$ pteronyssinus $\operatorname{IgG}_{1}$ antibodies in the children's sera.

The pattern of change in $D$ pteronyssinus $\operatorname{IgG}_{1}$ concentrations parallels changes in total IgG up to one year. The fall in concentrations at 24 months, however, suggests a specific immune response. A possible explanation for the fall is a reduction in the time spent maximally exposed to the antigen, as actual mite counts are unlikely to have altered drastically in every child's environment between the first and second years. Alternatively it could imply a switch in the subclass of IgG after prolonged exposure. $\mathrm{IgG}_{4}$ would be the obvious alternative subclass ${ }^{19}$ but no IgG4 antibodies to $D$ pteronyssinus were detected in any child at 24 months.

Measurements made at 3 months and before reflect maternal rather than the infants' own antibodies. Rises in specific $\mathrm{IgG}_{1}$ do occur between 7 days and 3 months, such as in IgG $_{1}$ to casein, ${ }^{20}$ indicating an infant response at this time. A similar response to the dust mite may be obscured by relatively high concentrations of maternal mite specific antibody in these children. By 6 months, and certainly by 12 months, most maternal antibody will have cleared. Measurements at these times are therefore a better indicator of the infant response. It may be that responsiveness to the dust mite is greatest in infancy and begins to wane thereafter.

$\mathrm{IgG}_{4}$ antibodies to $D$ pteronyssinus had been undetectable at all time points during the first year in the study of 'unselected' children. ${ }^{10}$ The present findings were similar. $D$ pteronyssinus $\mathrm{IgG}_{4}$ was only found in 7 day sera and every child with detectable concentrations had a mother who was allergic to the dust mite, reflecting the higher concentrations that might be expected in such mothers. ${ }^{21}$ These antibodies may take longer to appear. They are certainly not present in all adults. ${ }^{21}$

Prospective documentation of atopic manifestations in the large cohort of children allowed the present study to focus on the most obviously atopic and non-atopic individuals in an attempt to clarify possible differences in the response to the house dust mite.

Although the differences in $D$ pteronyssinus IgG $_{1}$ concentrations between atopic and nonatopic children at 6 and 12 months gave $0.01<p<0.05$, the statistical significance of these concentrations was interpreted cautiously in the light of multiple comparisons. The power calculation, however, indicated that significant differences smaller than $40-70 \mathrm{AU} / \mathrm{ml}$ might not be picked up by a study of the present size. Secondly the measurements were analysed according to atopic status as a means of grouping the children into those who were most likely 
and least likely to develop asthma. Differences in the $D$ pteronyssinus antibody response may have been more apparent had it been possible to identify the future asthmatic children with greater precision.

It has been suggested that aeroallergen exposure in early infancy may represent a critical time in determining subsequent sensitisation and disease manifestation. ${ }^{22}$ The present data intimates that $D$ pteronyssinus $\operatorname{IgG}_{1}$ antibody responses may be maximal during infancy. The highest $\operatorname{IgG}_{1}$ responses at 6 months and thereafter were not, however, seen in those who developed IgE sensitisation to the dust mite (fig 2). Dust mite sensitivity was based on data from the first two years of life. Out of 80 children in the cohort followed up to two years, only six had given positive skin prick tests to $D$ pteronyssinus of which five were in the present study. Clearly, many more of the children are likely to develop dust mite sensitivity when they are older.

This study demonstrates that IgG antibody responses to $D$ pteronyssinus during the first two years in children predisposed to atopic disease are predominantly in the $I G_{1}$ subclass. Higher $D$ pteronyssinus IgG $_{1}$ concentrations at one year than at two years may reflect greater exposure or responsiveness. Finally the tendency for higher $D$ pteronyssinus $\operatorname{IgG}_{1}$ concentrations at 6 and 12 months in children with atopic manifestation in the first two years may become more clear cut in later years when analyses are made according to the presence of asthma.

We would like to thank the children and their parents for participation in the study, Miss Maria Sorooshian for help with the total serum IgE measurements, Miss Fiona Reid for statistical advice, and the National Asthma Campaign, Children Nation wide, and the Wellcome Trust for generous support.

1 Platts-Mills TAE, de Weck AL. Dust mite allergens and asthma-a worldwide problem. F Allergy Clin Immunol 1989; 83:416-27.

2 Turner KJ, Stewart GA, Woolcock AJ, Green W, Alpers MP. Relationship between mite densities and the prevalence of asthma: comparative studies in two populations in the of asthma: comparative studies in two populations in the Eastern Highlan

3 Charpin D, Birnbaum J, Haddi E, et al. Altitude and allergy to house-dust mites. A paradigm of the influence of environmental exposure on allergic sensitization. Am Rev Respir Dis 1991;143:983-6.
4 Soothill JF, Stokes CR, Turner MW, Norman AP, Taylor B Predisposing factors and the development of reaginic allergy in infancy. Clinical Allergy 1976;6:305-19.

5 Warner JO, Price JF. House dust mite sensitivity in childhood asthma. Arch Dis Child 1978;53:710-3.

6 Businco L, Cantani A, Farinella F, Businco E. Month of birth and grass pollen or mite sensitization in children with respiratory allergy: a significant relationship. Clinical Allergy 1988;18:269-74.

7 Sporik R, Holgate ST, Platts-Mills TAE, Cogswell JJ. Exposure to house-dust mite allergen (Dep p I) and the development of asthma in childhood. A prospective study. N Engl F Med 1990;323:502-7.

8 Rowntree S, Cogswell JJ, Platts-Mills TAE, Mitchell EB. Development of IgE and IgG antibodies to food and Development of IgE and IgG antibodies to food and inhalant allergens in children

9 Van Asperen, Kemp AS. The natural history of IgE sensitisation and atopic disease in early childhood. Acta Paediatr Scand 1989;78:239-45.

10 Mariani F, Price JF, Kemeny DM. The IgG subclass antibody response to an inhalant antigen (Dermatophagoides pteronyssinus) during the first year of life: evidence for early stimulation of the immune system following natural exposure. Clin Exp Allergy 1992;22:29-34.

11 Calkhoven PG, Aalbers M, Schilte PPM, et al. Newly generated IgE antibodies to Dermatophagoides pteroynssinus in children are directed against components distinct from Der $\mathrm{p}$ I and Der $\mathrm{p}$ II. 7 Allergy Clin Immunol 1991;88. 265-71.

12 Sporik R Holgate ST Cogswell JJ Natural history of asthma in childhood: a birth cohort study. Arch Dis Child 1991;66: 1050-3.

13 Ruiz RGG, Richards D, Kemeny DM, Price JF. Neonatal IgE: a poor screen for atopic disease. Clin Exp Allergy 1991; 21:467-72

14 Hanifin JM, Rajka G. Diagnostic features of atopic dermatitis. Acta Dermatol Venereol 1980;92 (suppl):44-7.

15 Seymour JL, Keswick BH, Hanifin JM, Jordan WP, Milligan MC. Clinical effects of diaper types on the skin of normal infants and infants with atopic dermatitis. $\mathcal{f} \mathrm{Am}$ Acad Dermatol 1987;17:988-97.

16 Kemeny DM, Richards D, Johansson A, Durnin S. Ultrasensitive enzyme-linked immunosorbent assay (ELISA) for detection of picogram quantities of IgE. F Immunol Methods 1989;120:251-8

17 Kemeny DM, Richards D. ELISA for detection of total IgE: speed and sensitivity. In: Grange, Fox, Morgan, eds. Immunological techniques in microbiology. Oxford: Blackwell, 1987:47-58.

18 Kemeny DM, Urbanek R, Richards D, Greenall D. Development of a semi-quantitative enzyme-linked immunosorbent ment of a semi-quantitative enzyme-linked immunosorbent assay (ELISA) for detection of human I

19 Aalberse RC, van der Gaag R, van Leeuwen J. Serologic aspects of IgG4 antibodies. I. Prolonged immunization results in an IgG4-restricted response. F Immunol 1983;130: $722-6$

20 Kemeny DM, Price JF, Richardson V, Richards D, Lessof MH. The IgE and IgG subclass antibody response to foods in babies during the first year of life and their relationship to feeding regimen and the development of food allergy. f Allergy Clin Immunol 1991;87:920-9.

21 Kemeny DM, Urbanek R, Ewan P, et al. The subclass of IgG antibody in allergic disease: II. The IgG subclass of antibodies produced following natural exposure to dust mite and grass pollen in atopic and non-atopic individuals. Clin and grass pollen in atopic and

22 Warner JO, Warner JA. Aero-allergen avoidance in the prevention and treatment of asthma. Clin Exp Allergy 1990;20 (suppl 3):15-9. 